\title{
Substituted derivatives of indole acetic acid as aldose reductase inhibitors with antioxidant activity: structure-activity relationship
}

\author{
Maria Juskova ${ }^{1}$, Magdalena Majekova ${ }^{1}$, Vassilis Demopoulos ${ }^{2}$ and Milan Stefek ${ }^{1}$ \\ ${ }^{1}$ Institute of Experimental Pharmacology and Toxicology, Slovak Academy of Sciences, Dubravska cesta 9, 84104 Bratislava, \\ Slovak Republic \\ ${ }^{2}$ Aristotle University of Thessaloniki, School of Pharmacy, Department of Pharmaceutical Chemistry, Thessaloniki 541 24, Greece
}

\begin{abstract}
Although multiple biochemical pathways are likely to be responsible for the pathogenesis of diabetic complications, substantial evidence suggests a key role for the polyol pathway and oxidative stress initiated by hyperglycemia. Thus aldose reductase, the first enzyme of the polyol pathway, has been identified as a potential target of pharmacological intervention to prevent diabetic complications. Aldose reductase inhibitors endowed with antioxidant activity would be dually beneficial. The aim of the study was to evaluate the structure-activity relationship of commercially available indole derivatives supported by the molecular modeling of their interaction with the enzyme aldose reductase from the viewpoint of the inhibitory effect on the enzyme and their antioxidant activity. The partially purified aldose reductase was prepared from rabbit eye lenses. In vitro inhibiton of the aldose reductase was determined by a conventional method. Antioxidant action of the compounds was documented in a DPPH test. Marked differences were recorded in the aldose reductase inhibition activities of 1- and 3 -indole acetic acid derivatives. The interaction energies of the inhibitor $v s$. enzyme-NADP ${ }^{+}$complexes, calculated by computer aided molecular modeling, were in agreement with the higher inhibitory efficacy of 1 -indole acetic acid in contrast with 3 -indole acetic acid. The more efficient 1 -indole acetic acid was proved to create stronger electrostatic interaction with $\mathrm{NADP}^{+}$. However, the order of the antioxidant activities of the compounds studied was not in agreement with that of the inhibitory efficacies.
\end{abstract}

Key words: Indole acetic acid — Aldose reductase inhibition - Antioxidant — Diabetic complications

\section{Introduction}

Links between chronic hyperglycemia and the development of long-term diabetes-specific complications have been proved unequivocally (Brownlee 2005). Clinical studies have demonstrated that close control of blood glucose is significantly effective in reducing diabetic complications, but even optimal control of blood glucose can not prevent the onset of diabetes-related disorders in patients with longstanding disease, suggesting that alternative strategies are needed (Obrosova 2009). Among them, inhibition of aldose reductase (ALR2), the first enzyme of the polyol pathway, is considered a useful therapeutic approach to prevent the

Correspodence to: Milan Stefek, Institute of Experimental Pharmacology and Toxicology, Slovak Academy of Sciences, Dubravska cesta 9, 84104 Bratislava, Slovak Republic

E-mail: Milan.Stefek@savba.sk onset, or at least to delay the progression and the severity of diabetic complications (Alexiou et al. 2009).

Besides enhancing the flow rate of the polyol pathway, hyperglycemia may contribute to the development of pathological long-term complications by induction of oxidative stress (Baynes and Thorpe 1999). One of the key physiological roles of aldose reductase is the detoxification of toxic aldehydes, lipid peroxidation products, which arise under pathological conditions of oxidative stress. Thus in diabetic conditions, aldose reductase inhibition may have unwanted consequences. The side effect may even be enhanced due to a lack of selectivity for the closely related aldehyde reductase (ALR1), which shares its detoxification role with aldose reductase. In addition, ALR2 itself can be oxidatively modified to enzyme forms that are less sensitive to aldose reductase inhibitors (ARIs), which may affect their responsiveness to ALR2 inhibition therapy (Das and Srivastava 1985; Srivastava et al. 1985; Srivastava et al. 1986a,b; Chandra et al. 2002). 
Thus the effects of ARIs and antioxidants are unidirectional, i.e. both classes of agents interfere with molecular mechanisms involved in the etiology of diabetic complications. Parallel administration of antioxidants and ARIs can counterbalance inhibition of the detoxification role of ALR2. It seems clear that in the case of diseases of multifactorial origin, modulating a single target, even with a very efficient drug, is unlikely to yield the desired outcome. Innovative strategies are focused on rational design of chemical entities able to affect simultaneously multiple key mechanisms. This approach increases the chance of successful therapeutic intervention, decreases the risk of side effects and is economical. ARIs possessing antioxidant activity would therefore seem to be desirable. Compounds such as pyridazines (Coudert et al. 1994), benzopyranes (Costantino et al. 1999) and pyridopyrimidines (La Motta et al. 2007) have been synthesized and display antioxidant as well as aldose reductase inhibitory activities under in vitro conditions.

Recently novel carboxymethylated pyridoindoles, analogs of the efficient chain-breaking antioxidant stobadine, have been designed, synthesized and characterized as bifunctional compounds with joint antioxidant/aldose reductase inhibitory activities, with the potential of preventing diabetic complications (Stefek et al. 2008; Juskova et al. 2009, 2010). Other authors recorded the ALR2 inhibition activity of acidic derivatives of structurally related indoles (Da Settimo et al. 2003; Nicolaou and Demopoulos 2003; Sun et al. 2003; Suzen and Buyukbingol 2003; Suzen et al. 2007). The antioxidant activity of indole-based compounds has recently been thoroughly reviewed (Suzen 2006, 2007; Stolc et al. 2006; Suzen et al. 2006; Reiter et al. 2008; Au- gustyniak et al. 2010; Juranek et al. 2010; Shirinzadeh et al. 2010).

In the light of the above mentioned findings, we considered it interesting to analyze, both experimentally and theoretically by computer aided molecular modeling, the structural aspects of the ALR2 inhibition efficacy and antioxidant activity of 1- and 3-indole acetic acid derivatives shown in Figure 1. Considering the ubiquity of indoles in a wide range of natural products, we believe that the common indole core may represent a natural product scaffold as a starting point for "biologically oriented synthesis" (Wilk et al. 2010) of novel biology active agents, as indicated above.

\section{Materials and Methods}

\section{Animals}

Rabbits HIL (3.5 month old), were used as organ donors. The animals came from the Breeding Facility of the Institute of Experimental Pharmacology and Toxicology Dobra Voda (Slovak Republic). The study was approved by the Ethics Committee of the Institute and performed in accordance with the Principles of Laboratory Animal Care (NIH publication 83-25, revised 1985) and the Slovak law regulating animal experiments (Decree 289, Part 139, July 9th 2003).

\section{Preparation of ALR2}

ALR2 from rabbit lens was partially purified using a procedure adapted from Hayman and Kinoshita (1965) as fol-<smiles>O=C(O)Cn1ccc2ccccc21</smiles>

1-indole acetic acid

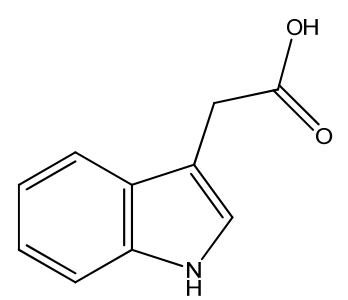

3-indole acetic acid<smiles>COc1ccc2[nH]cc(CC(=O)O)c2c1</smiles>

5-methoxy-3-indole acetic acid<smiles>COc1ccc2[nH]c(C)c(CC(=O)O)c2c1</smiles>

5-methoxy-2-methyl-3-indole acetic acid<smiles>C=C(O)Cc1c(C)n(C(=O)c2ccc(Cl)cc2)c2ccc(OC)cc12</smiles>

indomethacin

Figure 1. Structures of the commercially available indoles included in the study. 
lows: lenses were quickly removed from rabbits following euthanasia and homogenized in a glass homogenizer with a teflon pestle in 5 volumes of cold distilled water. The homogenate was centrifuged at $10000 \times g$ at $0-4^{\circ} \mathrm{C}$ for $20 \mathrm{~min}$. The supernatant was precipitated with saturated ammonium sulfate at $40 \%, 50 \%$ and then at $75 \%$ salt saturation. The supernatant was retained after the first two precipitations. The pellet from the last step, possessing ALR2 activity, was dispersed in $75 \%$ ammonium sulfate and stored in smaller aliquots in liquid nitrogen container.

\section{Enzyme assays}

ALR2 activities were assayed spectrophotometrically by determining NADPH consumption at $340 \mathrm{~nm}$ and were expressed as decrease of the optical density (O.D.)/s/mg protein (Da Settimo et al. 2005). The reaction mixture contained $4.67 \mathrm{mmol} / \mathrm{l}$ D,L-glyceraldehyde as a substrate, $0.11 \mathrm{mmol} / \mathrm{l} \mathrm{NADPH}, 0.067$ $\mathrm{mol} / \mathrm{l}$ phosphate buffer, $\mathrm{pH} 6.2$ and $0.05 \mathrm{ml}$ of the enzyme preparation in a total volume of $1.5 \mathrm{ml}$. The reference blank contained all the above reagents except the substrate D,L-glyceraldehyde to correct for oxidation of NADPH not associated with reduction of the substrate. The enzyme reaction was initiated by addition of D,L-glyceraldehyde and was monitored for $4 \mathrm{~min}$ after an initial period of $1 \mathrm{~min}$ at $30^{\circ} \mathrm{C}$. Enzyme activities were adjusted by diluting the enzyme preparations with distilled water so that $0.05 \mathrm{ml}$ of the preparation gave an average reaction rate for the control sample of $0.020 \pm 0.005$ absorbance units/min. The effect of inhibitors on the enzyme activity was determined by including in the reaction mixture each inhibitor at required concentrations. The inhibitor at the same concentration was included in the reference blank. Stock solutions of the inhibitors $(3 \mathrm{mmol} / \mathrm{l})$ were prepared in water by adding the equivalent amount of $\mathrm{NaOH}$ to facilitate dissolution. In the case of 1 -indole acetic acid, the $\mathrm{IC}_{50}$ value could be determined from the least-square analysis of the linear portion of the semilogarithmic inhibition curves. Each curve was generated using at least four concentrations of inhibitor causing an inhibition in the range from at least 25 to $75 \%$.

\section{DPPH test}

To investigate the antiradical activity of the indole acetic acid derivatives, the ethanolic solution of DPPH $(50 \mu \mathrm{mol} / \mathrm{l})$ was incubated in the presence of a compound tested $(200 \mu \mathrm{mol} / \mathrm{l})$ at laboratory temperature. The absorbance decrease, recorded at $\lambda_{\max }=518 \mathrm{~nm}$, during the first 30-min interval was taken as a marker of the antiradical activity.

\section{Computational methods}

The geometry of optimal conformers was obtained by conformational analysis by MMFF94 method and conse- quential optimization by DFT B3LYP/631-G* method in the program Spartan08 (Wavefunction, Inc., Irvine, CA, 2009). The geometry of the complex lidorestat-ALR2$\mathrm{NADP}+(1 \mathrm{z} 3 \mathrm{n})$ from the Protein Data $\mathrm{Bank}^{2}$ was chosen for molecular modelling. The docking of inhibitor was realized by program AutoDock 4.2. (Morris et al. 2009) and final optimization of enzyme-coenzyme-inhibitor complex was performed in the program VEGAZZ (Pedretti et al. 2004), from which also values of individual interaction energies (calculated by the force field CVFF) were obtained. Dielectric constant was set to value 2 (taking into account the interior of protein) and the original structure of $1 \mathrm{z} 3 \mathrm{n}$ was also relaxed till the energy tolerance was fulfilled $(0.1$ for conjugated gradient minimization). Visualization of the active site with inhibitor was realized by program Spartan08.

\section{Chemicals and instruments}

1-Indole acetic acid, 3-indole acetic acid, 5-methoxy-3-indole acetic acid, 5-methoxy-2-methyl-3-indole acetic acid, indomethacin and melatonin were obtained from SigmaAldrich (Steinheim, Germany). $\alpha, \alpha^{\prime}$-Diphenyl- $\beta$-picrylhydrazyl (DPPH) radical, NADPH, D,L-glyceraldehyde were obtained from Sigma Chemical Co. (St. Louis, MO, USA). Other chemicals were purchased from local commercial sources and were of analytical grade quality.

\section{Results}

As summarized in Table 1, the most efficient inhibitor of ALR2 is 1-indole acetic acid with $\mathrm{IC}_{50} \sim 7 \mu \mathrm{mol} / 1$. Structural variations of 3-indole acetic acid, e.g. 5-methoxy-3-indole acetic acid, indomethacin and its metabolite 5-methoxy2-methyl-3-indole acetic acid, did not result in significant changes in inhibition efficacy, characterized by the values of $\mathrm{IC}_{50}>100 \mu \mathrm{mol} / \mathrm{l}$.

The interaction energies of 1 - and 3-indole acetic acid $v s$. enzyme-NADP ${ }^{+}$complexes in comparison with reference

Table 1. Inhibition of rabbit lens aldose reductase

\begin{tabular}{ll}
\hline Compound & \multicolumn{1}{c}{ Inh (\%) } \\
\hline 1-indole acetic acid & $99.26 \pm 5.90$ \\
3-indole acetic acid & $38.36 \pm 3.94$ \\
5-methoxy-2-methyl-3-indole acetic acid & $35.59 \pm 12.47$ \\
indomethacin & $32.78 \pm 6.23$ \\
5-methoxy-3-indole acetic acid & $11.48 \pm 6.58$ \\
\hline
\end{tabular}

Inh (\%), percentage of ALR2 inhibition at inhibitor concentration of $100 \mu \mathrm{mol} / \mathrm{l}$. $\mathrm{IC}_{50}$ for 1 -indole acetic acid was $6.96 \pm 0.94 \mu \mathrm{mol} / \mathrm{l}$. Results are means $\pm \mathrm{SD}(n \geq 3)$. 
Table 2. Total and individual interaction energies between 1- and 3-indole acetic acids and ALR2

\begin{tabular}{llrcc}
\hline & & lidorestat & $\begin{array}{c}\text { 1-indole } \\
\text { acetic acid }\end{array}$ & $\begin{array}{c}\text { 3-indole } \\
\text { acetic acid }\end{array}$ \\
\hline $\mathrm{E}_{\text {int }}$ total & & -102.4 & -70.8 & -60.2 \\
\hline \multirow{3}{*}{ NADP $^{+}$} & total & -30.0 & -32.9 & -28.7 \\
& R6R12 & 8.0 & 17.9 & 11.7 \\
& elst & -38.0 & -50.7 & -40.4 \\
\cline { 2 - 5 } Tyr48 & total & 0.8 & -0.4 & 0.3 \\
& R6R12 & -2.5 & -3.3 & -2.9 \\
& elst & 3.3 & 2.9 & 3.2 \\
\cline { 2 - 5 } His110 & total & -4.0 & -3.8 & -3.4 \\
& R6R12 & -1.8 & -1.6 & -1.3 \\
& elst & -2.2 & -2.2 & -2.1 \\
\cline { 2 - 5 } Trp111 & total & -12.8 & -2.9 & -2.9 \\
& R6R12 & -12.5 & -3.1 & -3.1 \\
& elst & -0.3 & 0.2 & 0.2 \\
\hline
\end{tabular}

Individual interaction energies are divided into non-electrostatic (R6R12) and electrostatic (elst) contributions.

lidorestat, calculated by computer aided molecular modeling are summarized in Table 2.

Antioxidant activity of the indole derivatives was studied by a DPPH test. In Table 3 the compounds studied are arranged according to decreasing ability to eliminate the stable free radical of DPPH.

\section{Discussion}

\section{Aldose reductase inhibition}

Compared to our finding for indomethacin inhibition of rabbit ALR2 (32.8\% inhibition at $100 \mu \mathrm{mol} / \mathrm{l})$, Chaudhry et

Table 3. Antiradical activity of the indole derivatives in a DPPH test

\begin{tabular}{lc}
\hline Compound & $\begin{array}{c}\text { Absorbance decrease } \\
(-\Delta \mathrm{A} / 30 \mathrm{~min})\end{array}$ \\
\hline 5-methoxy-2-methyl-3-indole acetic acid & $0.1075 \pm 0.012$ \\
5-methoxy-3-indole acetic acid & $0.0885 \pm 0.014$ \\
3-indole acetic acid & $0.0688 \pm 0.014$ \\
indomethacin & $0.0467 \pm 0.017$ \\
melatonin & $0.0220 \pm 0.006$ \\
1-indole acetic acid & $0.0007 \pm 0.008$ \\
\hline
\end{tabular}

Ethanolic solution of DPPH radical $(50 \mu \mathrm{mol} / \mathrm{l})$ was incubated in the presence of the compounds tested $(200 \mu \mathrm{mol} / \mathrm{l})$. Absorbance decrease at $518 \mathrm{~nm}$ during the initial 30 -min period was determined. Results are means $\pm \operatorname{SD}(n \geq 3)$. al. 1983 reported one order higher efficacy (34\% inhibition at $10 \mu \mathrm{mol} / \mathrm{l}$ concentration) in relation to human ALR2 isolated from eye lenses. The ALR2 inhibition activities of structurally related derivatives were recorded, namely those of 1 -indole butanoic acid with $\mathrm{IC}_{50}$ values ranging from 7.4 to $37 \mu \mathrm{mol} / 1$ (Sun et al. 2003), cyano(2-oxo-2,3-dihydroindole-3-ylidene) acetic acid with $\mathrm{IC}_{50}$ varying from 0.075 to $5.40 \mu \mathrm{mol} / \mathrm{l}(\mathrm{Da}$ Settimo et al. 2003) and (3-benzoylindol-1-yl)acetic acid with $38 \%$ ALR2 inhibition at $1 \mu \mathrm{mol} / \mathrm{l}$ concentration (Nicolaou and Demopoulos 2003). Mild ALR2 inhibitory activity of 2phenylindole derivatives was recorded by Suzen et al. (2007). In the light of the above mentioned results, it appeared interesting to analyze the structural aspects of the marked difference in the inhibition activities of 1 - and 3-indole acetic acids, since the common indole core may represent a natural product scaffold as a starting point for biologically oriented synthesis of efficient ARIs.

Lidorestat (Figure 2) and its substitution congeners, derivatives of 1-indole acetic acid (Van Zandt et al. 2005, 2006), belong among the most efficient inhibitors of ALR2 with $\mathrm{IC}_{50}$ values in the nmol/l region and with very good ALR2/ALR1 selectivity values. We used the available structure of lidorestat-ALR2 complex (pdb structure 1z3n) for comparative molecular modeling studies of 1- vs. 3-indole acetic acids. As reported by Van Zandt et al. (2005), lidorestat was found to interfere with ALR2 via two important structural components: i) carboxymethylated indole, which binds to His ${ }^{110}$, $\operatorname{Trp}^{111}$, Tyr ${ }^{48}$ and NADP ${ }^{+}$, the principal residues of the active site, ii) substituted benzothiazole, which stabilizes the binding of lidorestat through its $\pi$-stacking interaction with the indole moiety of $\operatorname{Trp}^{111}$ and hydrogen bonding between the amide $\mathrm{N}-\mathrm{H}$ of Leu ${ }^{300}$ and the benzothiazole $\mathrm{N}$ and 4'fluorine. According to our calculations (Table 2), the former component ensures the main part of the binding, which is mainly of electrostatic nature due to $-\mathrm{COO}^{-}$and $\mathrm{NADP}^{+}$interaction. On the other hand, as expected, the calculated interaction energies, presented in Table 2, are in accord with the notion

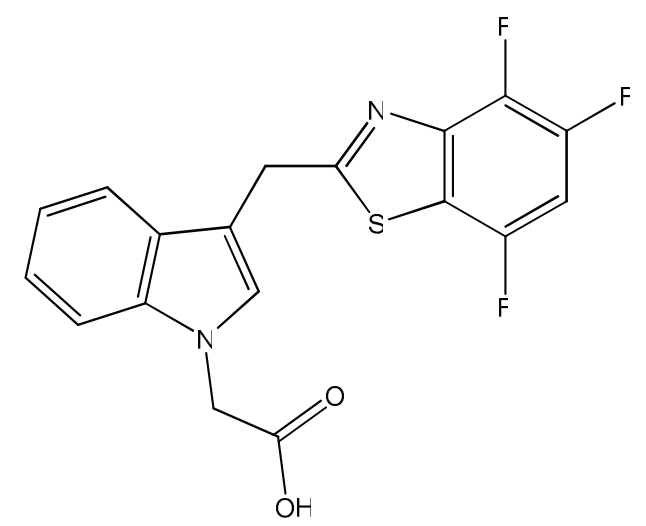

Figure 2. Structure of lidorestat. 
that the interaction of the benzothiazole moiety with Trp ${ }^{111}$ is mainly non-electrostatic.

In contrast to lidorestat, both molecules under study, 1 -indoleacetic acid and 3-indole acetic acid, lack additional structural moiety able to stabilize total interaction with the ALR2-NADP $^{+}$complex. However, as seen in Table 2, their interaction energies $\left(\mathrm{E}_{\text {int }}\right)$ with $\mathrm{NADP}^{+}$, which create the fundamental part of total interaction energy, remain almost the same as for lidorestat itself. The larger value for 1-indole acetic acid $(-32.9 \mathrm{kcal} / \mathrm{mol})$ in comparison with 3 -indole acetic acid $(-28.7 \mathrm{kcal} / \mathrm{mol}) \mathrm{can}$ be related also to the different dipole values for the original optimized structures (1.8 D for former and $0.8 \mathrm{D}$ for latter).
Based on the distances of the potential partners of the crucial hydrogen bonds between the carboxylic group of the inhibitor and the components of the enzyme binding site, both 1- and 3-indole acetic acid are supposed to create $\mathrm{H}$-bonds both with $\mathrm{Tyr}^{48}$ and His ${ }^{110}$, the residues of the anionic inhibitor binding site of the enzyme (Varnai and Warshel 2000). In addition, 1-indole acetic acid is in a more favorable range of the electrostatic interaction with $\mathrm{NADP}^{+}$ (Figure 3).

The results of molecular modeling are in agreement with experimentally determined higher inhibition efficacy of 1 -indole acetic acid in comparison with 3 -indole acetic acid.
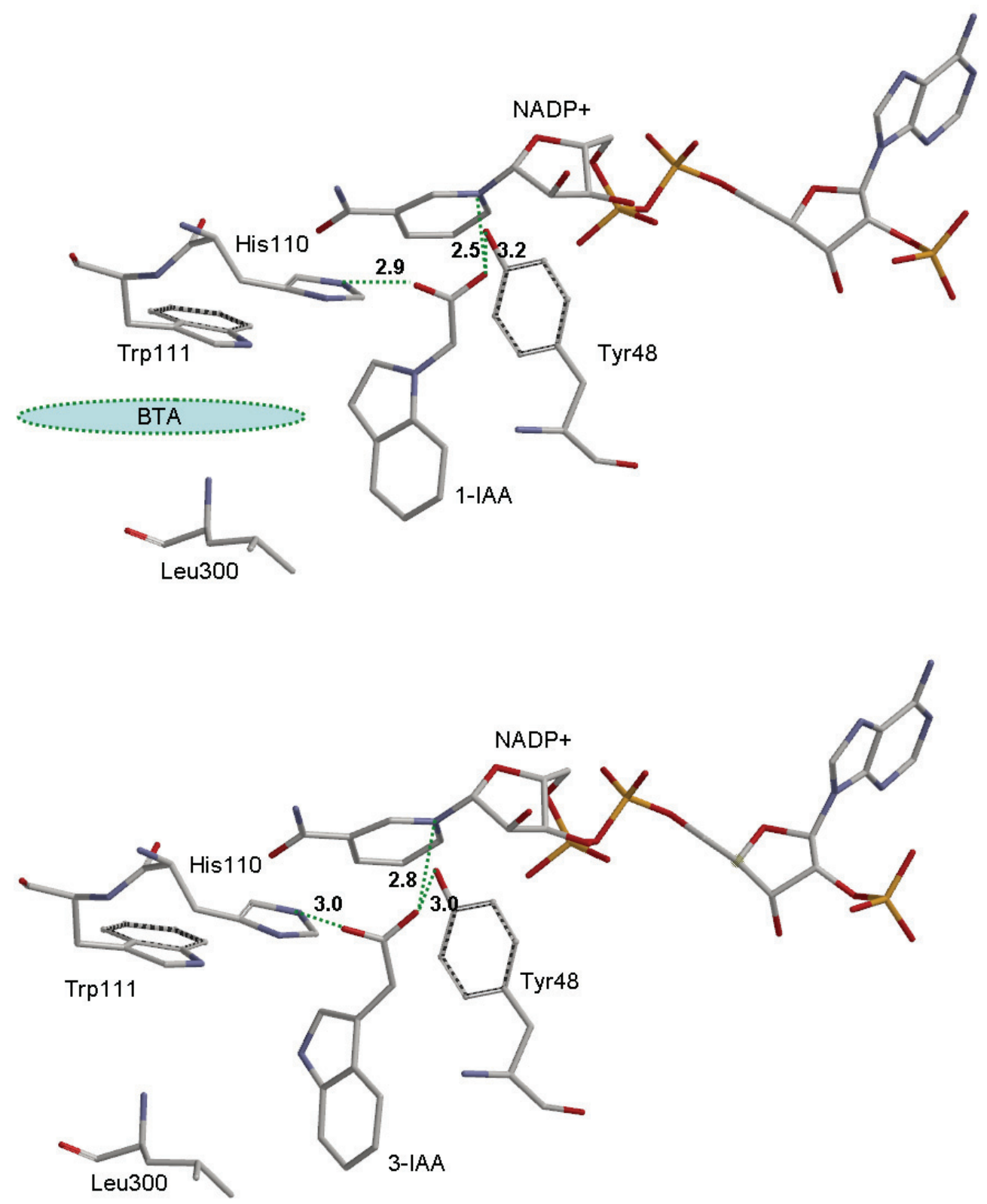

Figure 3. Geometry of the active site for 1-indole acetic acid (up) and 3-indole acetic acid (down) optimized with the whole enzyme-NADP ${ }^{+}$ complex. Dashed line denotes the hydrogen bonds between the carboxylic oxygens and the hydrogens of $\mathrm{His}^{110}$, Tyr ${ }^{48}$ and the positively charged nitrogen of $\mathrm{NADP}^{+}$. The ellipse on the left side points to the place where benzothiazole (BTA) ring of lidorestat creates significant additive stabilizing interactions with $\operatorname{Trp}^{111}$ and Leu $300^{31}$. 


\section{Antioxidant activity}

$\mathrm{DPPH}$, as a weak hydrogen atom abstractor, is considered a good kinetic model for peroxyl ROO (Blois 1958). All compounds studied, with exception of 1 -indole acetic acid, were found to have higher antiradical activity in comparison with melatonin, a 3-substituted indole derivative used as a structurally related reference antioxidant. The absence of the scavenging ability of 1-indole acetic acid is in compliance with the notion according to which the prerequisite of the antiradical activity of the indole derivatives is the presence of free hydrogen at this nitrogen (Rackova et al. 2002). By its splitting, resonance stabilized indolyl radical is created, the stability of which is affected by the presence of aromatic substituents. Electron donor substituents in the positions orto and para facilitate delocalization of the unpaired electron of the indolyl radical and increase its stability (Rackova et al. 2006). In the case of 1-indole acetic acid, an optional pathway proposed for the interaction of $\mathrm{N}$-substituted indoles with radicals proceeding via electron donation (Reiter et al. 1997; Andreadou et al. 2003) is not obviously valid.

In the group of the 3-indole acetic acid derivatives increased activity of the methoxy derivatives was observed (5-methoxy-2-methyl-3-indole acetic acid and 5-methoxy3 -indole acetic acid) in comparison with 3-indole acetic acid alone. Antioxidant activity of indomethacin, well documented by other authors (Prasad and Laxdal 1994; Kataoka et al. 1997; Stetinova et al. 2002; Fernandes et al. 2004; Costa et al. 2005), results from the conjugation of the aryl substituent with the indole skeleton (Fernandes et al. 2004).

\section{Conclusions}

Marked differences were recorded in aldose reductase inhibition activities of 1 - and 3 -indole acetic acid derivatives. The interaction energies of the inhibitor $v s$. enzyme-NADP ${ }^{+}$ complex, calculated by computer aided molecular modeling, were in agreement with the higher inhibitory efficacy of 1 -indole acetic acid in contrast with 3 -indole acetic acid. The more efficient 1 -indole acetic acid was proved to create stronger electrostatic interaction with $\mathrm{NADP}^{+}$. However, the order of the antioxidant activities of the compounds studied was not in agreement with that of the inhibitory efficacies.

The results have envisaged design of two lines of potentially biologically active compounds, with relevance ( $v i a$ the common indole core) to nature, based on: i) 3-indole acetic acid as a lead for design and optimization of multitarget-oriented compounds with antioxidant efficacy surpassing that of melatonin, yet with mild ARI activity; ii) 1-indole acetic acid as a lead structure, optimization of which may result in highly efficient ARIs, yet devoid of antioxidant action.
Acknowledgements. This work was supported by VEGA Grant No. 2/0067/11, No. 2/0030/11 and APVV No. 51-017905.

\section{References}

Alexiou P., Pegklidou K., Chatzopoulou M., Nicolaou I., Demopoulos V. J. (2009): Aldose reductase enzyme and its implication to major health problems of the 21(st) century. Curr. Med. Chem. 16, 734-752

http://dx.doi.org/10.2174/092986709787458362

Augustyniak A., Bartosz G., Cipak A., Duburs G., Horakova L., Luczaj W., Majekova M., Odysseos A. D., Rackova L., Skrzydlewska E., Stefek M., Strosova M., Tirzitis G., Venskutonis P. R., Viskupicova J., Vraka P. S., Zarkovic N. (2010): Natural and synthetic antioxidants: an updated overview. Free Radic. Res. 44, 1216-1262 http://dx.doi.org/10.3109/10715762.2010.508495

Baynes J. W., Thorpe S. R. (1999): Role of oxidative stress in diabetic complications: a new perspective on an old paradigm. Diabetes 48, 1-9 http://dx.doi.org/10.2337/diabetes.48.1.1

Blois M. S. (1958): Antioxidant determinations by the use of a stable free radical. Nature 181, 1199-1200 http://dx.doi.org/10.1038/1811199a0

Brownlee M. (2005): The pathobiology of diabetic complications. A unifying mechanism. Diabetes 54, 1615-1625 http://dx.doi.org/10.2337/diabetes.54.6.1615

Chandra D., Jackson E. B., Ramana K. V., Kelley R., Srivastava S. K., Bhatnagar A. (2002): Nitric oxide prevents aldose reductase activation and sorbitol accumulation during diabetes. Diabetes 51, 3095-3101 http://dx.doi.org/10.2337/diabetes.51.10.3095

Chaudhry P. S., Cabrera J., Juliani H. R., Varma S. D. (1983): Inhibition of human lens aldose reductase by flavonoids, sulindac and indomethacin. Biochem. Pharmacol. 32, 1995-1998 http://dx.doi.org/10.1016/0006-2952(83)90417-3

Costa D., Gomes A., Reis S., Lima J. L., Fernandes E. (2005): Hydrogen peroxide scavenging activity by non-steroidal antiinflammatory drugs. Life Sci. 76, 2841-2848 http://dx.doi.org/10.1016/j.lfs.2004.10.052

Costantino L., Rastelli G., Gamberini M. C., Vinson J. A., Bose P., Iannone A., Staffieri M., Antolini L., Del Corso A., Mura U., Albasini A. J. (1999): 1-Benzopyran-4-one antioxidants and aldose reductase inhibitors. J. Med. Chem. 42, 1881-1893 http://dx.doi.org/10.1021/jm980441h

Coudert P., Albuisson E., Boire J. Y., Duroux E., Bastide P., Couquelet J. (1994). Synthesis of pyridazine acetic acid derivatives possessing aldose reductase inhibitory activity and antioxidant properties. Eur. J. Med. Chem. 29, 471-477 http://dx.doi.org/10.1016/0223-5234(94)90074-4

Da Settimo F., Primofiore G., Da Settimo A., La Motta C., Simorini F., Novellino E., Greco G., Lavecchia A., Boldrini E. J. (2003): Novel, highly potent aldose reductase inhibitors: cyano(2-oxo2,3-dihydroindol-3-yl)acetic acid derivatives. J. Med. Chem. 46, 1419-1428 http://dx.doi.org/10.1021/jm030762f 
Da Settimo F., Primofiore G., La Motta C., Salerno S., Novellino E., Greco G., Lavecchia A., Laneri S., Boldrini E. (2005): Spirohydantoin derivatives of thiopyrano[2,3-b]pyridin-4(4H)-one as potent in vitro and in vivo aldose reductase inhibitors. Bioorg. Med. Chem. 13, 491-499 http://dx.doi.org/10.1016/j.bmc.2004.10.019

Das B., Srivastava S. K. (1985): Activation of aldose reductase from human tissues. Diabetes 34, 1145-1151 http://dx.doi.org/10.2337/diabetes.34.11.1145

Fernandes E., Costa D., Toste S. A., Lima J. L., Reis S. (2004): In vitro scavenging activity for reactive oxygen and nitrogen species by nonsteroidal anti-inflammatory indole, pyrrole, and oxazole derivative drugs. Free Radic. Biol. Med. 37, 1895-1905 http://dx.doi.org/10.1016/j.freeradbiomed.2004.09.001

Hayman S., Kinoshita J. H. (1965): Isolation and properties of lens aldose reductase. J. Biol. Chem. 240, 877-882

Juranek I., Horakova L., Rackova L., Stefek M. (2010): Antioxidants in treating pathologies involving oxidative damage: an update on medicinal chemistry and biological activity of stobadine and related pyridoindoles. Curr. Med. Chem. 17, 552-570 http://dx.doi.org/10.2174/092986710790416317

Juskova M., Snirc V., Gajdosikova A., Gajdosik A., Krizanova L, Stefek M. (2009): Carboxymethylated tetrahydropyridoindoles as aldose reductase inhibitors: in vitro selectivity study in intact rat erythrocytes in relation to glycolytic pathway. Gen. Physiol. Biophys. 28, 325-330 http://dx.doi.org/10.4149/gpb_2009_04_325

Juskova M., Snirc V., Krizanova L., Stefek M. (2010): Effect of carboxymethylated pyridoindoles on free radical-induced haemolysis of rat erythrocytes in vitro. Acta Biochim. Pol. 57, $153-156$

Kataoka M., Tonooka K., Ando T., Imai K., Aimoto T. (1997): Hydroxyl radical scavenging activity of nonsteroidal anti-inflammatory drugs. Free Radic. Res. 27, 419-427 http://dx.doi.org/10.3109/10715769709065781

La Motta C., Sartini S., Mugnaini L., Simorini F., Taliani S., Salerno S., Marini A. M., Da Settimo F., Lavecchia A., Novellino E., Cantore M., Failli P., Ciuffi M. J. (2007): Pyrido[1,2-a] pyrimidin-4-one derivatives as a novel class of selective aldose reductase inhibitors exhibiting antioxidant activity. J. Med. Chem. 50, 4917-4927 http://dx.doi.org/10.1021/jm070398a

Morris G. M., Huey R., Lindstrom W., Sanner M. F., Belew R. K., Goodsell D. S., Olson A. J. (2009): Autodock4 and AutoDockTools4: automated docking with selective receptor flexiblity. J. Comput. Chem. 30, 2785-2791

http://dx.doi.org/10.1002/jcc.21256

Nicolaou I., Demopoulos V. J. (2003): Substituted pyrrol-1-ylacetic acids that combine aldose reductase enzyme inhibitory activity and ability to prevent the nonenzymatic irreversible modification of proteins from monosaccharides. J. Med. Chem. 46, 417-426 http://dx.doi.org/10.1021/jm0209477

Obrosova I. G. (2009): Diabetes and the peripheral nerve. Biochim. Biophys. Acta 1792, 931-940

Pedretti A., Villa L., Vistoli G. (2004): VEGA - an open platform to develop chemo-bio-informatics applications, using plug-in architecture and script programming. J. Comput. Aided Mol. Des. 18, 167-173
http://dx.doi.org/10.1023/B:JCAM.0000035186.90683.f2

Prasad K., Laxdal V. A. (1994): Hydroxyl radical-scavenging property of indomethacin. Mol. Cell. Biochem. 136, 139-144 http://dx.doi.org/10.1007/BF00926074

Rackova L., Stefek M., Majekova M. (2002): Structural aspects of antioxidant activity of substituted pyridoindoles. Redox Rep. $7,207-214$ http://dx.doi.org/10.1179/135100002125000578

Rackova L., Snirc V., Majekova M., Majek P., Stefek M. (2006): Free radical scavenging and antioxidant activities of substituted hexahydropyridoindoles. Quantitative structure-activity relationships. J. Med. Chem. 49, 2543-2548 http://dx.doi.org/10.1021/jm060041r

Reiter R. J., Tan D. X., Jou M. J., Korkmaz A., Manchester L. C., Paredes S. D. (2008): Biogenic amines in the reduction of oxidative stress: melatonin and its metabolites. Neuro Endocrinol. Lett. 29, 391-398

Shirinzadeh H., Eren B., Gurer-Orhan H., Suzen S., Ozden S. (2010): Novel indole-based analogs of melatonin: synthesis and in vitro antioxidant activity studies. Molecules 15, 2187-2202 http://dx.doi.org/10.3390/molecules15042187

Srivastava S. K., Hair G. A., Das B. (1985): Activated and unactivated forms of human erythrocyte aldose reductase. Proc. Natl. Acad. Sci. U.S.A. 82, 7222-7226 http://dx.doi.org/10.1073/pnas.82.21.7222

Srivastava S. K., Ansari N. H., Hair G. A., Awasthi S., Das B. (1986a): Activation of human erythrocyte, brain, aorta, muscle, and ocular tissue aldose reductase. Metabolism 35, 114-118 http://dx.doi.org/10.1016/0026-0495(86)90199-X

Srivastava S. K., Ansari N. H., Hair G. A., Jaspan J., Rao M. B., Das B. (1986b): Hyperglycemia-induced activation of human erythrocyte aldose reductase and alterations in kinetic properties. Biochim. Biophys. Acta 870, 302-311 http://dx.doi.org/10.1016/0167-4838(86)90234-7

Stefek M., Snirc V., Djoubissie P. O., Majekova M., Demopoulos V., Rackova L., Bezakova Z., Karasu Ç., Carbone V., El Kabbani O. (2008): Carboxymethylated pyridoindole antioxidants as aldose reductase inhibitors: Synthesis, activity, partitioning, and molecular modelling. Bioorg. Med. Chem. 16, 4908-4920 http://dx.doi.org/10.1016/j.bmc.2008.03.039

Stolc S., Snirc V., Majekova M., Gasparova Z., Gajdosikova A., Stvrtina S. (2006): Development of the new group of indolederived neuroprotective drugs affecting oxidative stress. Cell. Mol. Neurobiol. 26, 1495-1504 http://dx.doi.org/10.1007/s10571-006-9037-9

Stetinova V., Smetanova L., Grossmann V., Anzenbacher P. (2002): In vitro and in vivo assessment of the antioxidant activity of melatonin and related indole derivatives. Gen. Physiol. Biophys. 21, 153-162

Sun W. S., Park Y. S., Yoo J., Park K. D., Kim S. H., Kim J. H., Park H. J. (2003): Rational design of an indolebutanoic acid derivative as a novel aldose reductase inhibitor based on docking and 3D QSAR studies of phenethylamine derivatives. J. Med. Chem. 46, 5619-5627 http://dx.doi.org/10.1021/jm0205346 
Suzen S., Buyukbingol E. (2003): Recent studies of aldose reductase enzyme inhibition for diabetic complications. Curr. Med. Chem. 10, 1329-1352 http://dx.doi.org/10.2174/0929867033457377

Suzen S., Bozkaya P., Coban T., Nebioğu D. J. (2006): Investigation of the in vitro antioxidant behaviour of some 2-phenylindole derivatives: discussion on possible antioxidant mechanisms and comparison with melatonin. J. Enzyme Inhib. Med. Chem. 21, 405-411 http://dx.doi.org/10.1080/14756360500381210

Suzen S. (2006): Recent developments of melatonin related antioxidant compounds. Comb. Chem. High Throughput Screen. 9, 409-419

http://dx.doi.org/10.2174/138620706777698553

Suzen S. (2007): Antioxidant activities of synthetic indole derivatives and possible activity mechanisms. Top Heterocycl. Chem. 11, 145-178

Suzen S., Das-Evcimen N., Varol V., Sarıkaya M. (2007): Preliminary evaluation of rat kidney aldose reductase inhibitory activity of 2-phenylindole derivatives: affiliation to antioxidant activity. Med. Chem. Res. 16, 112-118 http://dx.doi.org/10.1007/s00044-007-9014-y

Van Zandt M. C., Jones M. L., Gunn D. E., Geraci L. S., Jones J. H., Sawicki D. R., Sredy J., Jacot J. L., Dicioccio A. T., Petrova
T., Mitschler A., Podjarny A. D. (2005): Discovery of 3[(4,5,7-trifluorobenzothiazol-2-yl)methyl]indole- $\mathrm{N}$-acetic acid (lidorestat) and congeners as highly potent and selective inhibitors of aldose reductase for treatment of chronic diabetic complications. J. Med. Chem. 48, 3141-3152 http://dx.doi.org/10.1021/jm0492094

Van Zandt M. C., Doan B., Sawicki D. R., Sredy J., Podjarny A. D. (2009): Discovery of [3-(4,5,7-trifluoro-benzothiazol-2-ylmethyl)-pyrrolo[2,3-b]pyridin-1-yl]acetic acids as highly potent and selective inhibitors of aldose reductase for treatment of chronic diabetic complications. Bioorg. Med. Chem. Lett. 19, 2006-2008 http://dx.doi.org/10.1016/j.bmcl.2009.02.037

Varnai P., Warshel A. (2002): Computer simulation studies of the catalytic mechanism of human aldose reductase. J. Am. Chem. Soc. 122, 3849-3860 http://dx.doi.org/10.1021/ja994246j

Wilk W., Zimmermann T. J., Kaiser M., Waldmann H. (2010): Principles, implementation, and application of biology-oriented synthesis (BIOS). Biol. Chem. 391, 491-497 http://dx.doi.org/10.1515/BC.2010.013

Received: February 18, 2011

Final version accepted: June 23, 2011 